The final publication is available at Springer via http://dx.doi.org/10.1007/s40292-015-0101-8 


\section{A Persian Adaptation of Medication Adherence Self-Efficacy 3 Scale (MASES) in Hypertensive Patients: Psychometric Properties 4 and Factor Structure}

5 Mohsen Saffari ${ }^{1}$ - Isa Mohammadi Zeidi ${ }^{2} \cdot$ Bengt Fridlund $^{3}$.

6 Hui Chen ${ }^{4} \cdot$ Amir H. Pakpour ${ }^{1,5}$

7 Received: 2 March 2015/ Accepted: 9 May 2015

8 (C) Springer International Publishing Switzerland 2015

\section{Abstract}

A7 3 School of Health Sciences, Jönköping University, Jönköping, A8 Sweden

A9 4 School of Life Sciences, Faculty of Science, University of

A10 Technology, Sydney, NSW, Australia

A11 5 Social Determinants of Health Research Center, Qazvin

A12 University of Medical Sciences, Shahid Bahonar Blvd,

A13 Qazvin, Iran uncontrolled hypertension showed poor adherence to hypertensive medications, therefore had significant lower self-efficacy scores than those with well-controlled blood pressure by medication.

Conclusion The Persian version of MASES is valid and reliable to assess self-efficacy of anti-hypertension medication adherence in hypertensive patient, which is helpful to improve medication compliance in such patients in order to achieve better blood pressure control.

Keyword Hypertension - Blood pressure control · Self-efficacy

\section{Introduction}

Hypertension is one of the major causes of cerebrovascular and cardiovascular diseases and related mobility and motility. Hypertension is usually a chronic asymptomatic condition. It is estimated that worldwide about $60 \%$ of the adult population will develop hypertension in year 2025 . Compared to the developed countries, the risk of hypertension in the developing countries has almost been doubled, including Iran [1]. Uncontrolled hypertension is defined as systolic blood pressure greater than $140 \mathrm{mmHg}$ or diastolic blood pressure greater than $90 \mathrm{mmHg}$. However, according to the latest recommendation of European Society of Hypertension, an ideal target blood pressure is less than 140/85 mmHg [2, 3]. In most cases, lifestyle modification and anti-hypertensive drugs are necessary to maintain an ideal blood pressure in order to reduce the risk of developing cerebrovascular and cardiovascular diseases [4].

Only a third of the patients with hypertension have adequate control over their blood pressure levels [5].
42 
Despite active and intensive drug treatment and increased awareness, the blood pressure in hypertensive patients is still poorly controlled in many countries [6]. Poor adherence to anti-hypertensive treatment has been shown to significantly contribute to the failure to achieve the goals of blood pressure management in the Seventh Report of the Joint National Committee on Prevention, Detection, Evaluation and Treatment of High Blood Pressure, which is unfortunately a global phenomenon [7]. Even with the access to effective anti-hypertensive medications, more than half of the patients spontaneously stopped their medication within the first year after the treatment initiated. Moreover, among the patients who have long-term hypertension, $50 \%$ of them received more than $80 \%$ of total prescribed medications [8]. As a result of poor adherence to anti-hypertensive medications, approximately $75 \%$ of hypertensive patients cannot achieve good control of their blood pressure [8].

Medication-taking behavior is a complex interaction between the biological, psychological and social factors [9]. There are several theories to explain the adherence behavior in hypertensive patients $[10,11]$. The theory that is well regarded is the self-efficacy theory. Self-efficacy is defined as the perception of one's ability to complete a take, a goal, or a specific challenge [12]. Self-efficacy has been considered as the most prominent predictor for health related behavioral change, such as adherence to medications in patients with chronic diseases [9]. Hypertensive patients with high levels of self-efficacy are more likely to feel confident to adhere to their medications $[9,13]$.

Self-efficacy is a type of self-assessment and self-confidence to perform a specific task, related to this study, the adherence to hypertensive medications. According to Bandura, it is one of the most important psychological factors that impact on medication adherence [14]. There are increased evidence on the effects of social learning, specifically self-efficacy, on the improvement of adherence over the past two decades [13]. Self-efficacy has been shown to be able to predict medication adherence in individuals diagnosed with chronic diseases [9]. McCann and colleagues considered self-efficacy as a "cornerstone of medication adherence" [15]. While there are discrepancy in the specific types of self-efficacy for different treatments, domestic specific self-efficacy is the form that impacts on the treatment process and outcome [16].

Therefore, Ogedegbe and colleagues developed the Medication Adherence Self-Efficacy Scale (MASES) to measure and identify situations in which patients expressed concerns about self-efficacy in adherence to prescribed medications [9]. It is designed to evaluate those who have struggled with blood pressure controls due to poor adherence to prescribed antihypertensive medications. The development of the $\mathrm{MASE}_{\mathrm{\Lambda}}$ was based on the results from open-ended interviews with 106 patients on their experience ${ }_{\lambda}$ with anti-hypertensive medications. Responses were divided into nine qualitative categories with 43 questions to cover the barriers and facilitators to medication adherence. MASES can also be used as a research tool to assess the effectiveness of a behavioral intervention program to enhance patients' self-efficacy $[9,17,18]$.

Several studies have investigated the medication compliance among different cohorts of patients in Iran; however, none of these studies have assessed the medication adherence using MASES, nor in hypertensive patients with uncontrolled blood pressure. Thus, to assess the compliance of anti-hypertensive medication in Iranian patients with hypertension toward, we need a tool that is compatible with the cultural background. Therefore, this study aimed to, (1) translate the English version of Ogedegbe's MASE into a Persian version, and; (2) examine the reliability and validity in patients with hypertension in Iran.

\section{Material and Methods}

\subsection{Translation of the English Version into a Persian Version}

An agreement to translate the original MASE $\mathrm{E}_{\alpha}$ questionnaire was obtained by the authors. The first stage of cultural adaptation was the translation of English questionnaire into Persian language, which was performed by two translators who are native English speakers and fluent in Persian language (forward translation). One of the translators was informed of the objectives and concepts of the questionnaire, whereas the other one was blind. This stage resulted in two translated versions. The differences between the two versions were compared and resolved between the two translators to yield the first final version [19].

The English version of the MASES was again translated by a native Iranian linguist, who is fluent in English and was unaware of the purpose of the questionnaire. The second translator is an Iranian cardiologist who was informed of the objectives of the current study. Both versions were assessed and consolidated between the researcher and the translator into a second final version.

Both final versions were translated back into English by another two native Persian-speaking translators who are fluent in English. These two translators did not receive any information on the concepts and purposes of the questionnaire. This procedure is the quality control of the accuracy during the translation [19].

Then, the Persian questionnaire was completed by 20 hypertensive patients who were randomly selected from those who were excluded from the main study, in order to evaluate and validate the translated questionnaire. The data

\begin{tabular}{|l|lll|}
\hline & Journal : Large 40292 & Dispatch : 13-5-2015 & Pages : 9 \\
Article No. : $\mathbf{1 0 1}$ & $\square$ & $\square$ TYPESET \\
MS Code : BPCP-D-15-00018 & $\checkmark$ CP & $\checkmark$ DISK \\
\hline
\end{tabular}


of questionnaires were collected anonymously by the authors for later evaluation. The difficulty level of the Persian questionnaire were then evaluated by a panel of experts in psychology, cardiology, and general practice who are experienced in hypertension diagnosis and treatment, as well as five hypertensive patients with different education levels. Based on the assessment outcome, the questionnaire was modified accordingly. In addition, lay language has been used to replace the medical terminology. Subsequently, the final version was again translated from Persian into English by two bilingual translators independently, who were unaware about the original English version of the questionnaire. The discrepancies between the two translated versions were again consolidated and the final version of Persian MASE $_{\Lambda}$ questionnaire was completed for a formal assessment in hypertensive patients who met the selection criteria.

\subsection{The Evaluation of Validity and Reliability}

The confidence of the questionnaire was evaluated using internal consistency and re-tests reliability. Cronbach's alpha coefficient was used to assess the internal consistency [20]. Interpretation of Item-total scale correlation was used to assess the reliability of the questionnaire. These coefficients were only acceptable if the value of the Self-efficacy, the perception of one's ability to complete a task, a goal or a specific challenge (ICC) was greater than 0.3 and Cronbach's alpha was equal to or greater than 0.7.

The exploratory Factor Analysis was used to assess the factor structure of the questionnaire, and principal component analysis was performed. Several tests were used to assess the suitability of the respondent data before the Factor Analysis, including Kaiser-Meyer-Olkin (KMO) Measure of Sampling Adequacy, and Bartlett's Test of Sphericity. The KMO index is required when the case to variation ratio is less than 1:5. The KMO index is ranged from 0 to 1 , with greater than 0.50 considered as suitable for Factor Analysis. The Factor Analysis is only applicable when the Bartlett's Test of Sphericity is significant $(\mathrm{P}<0.05)$. In order to determine the group validity, MASES survey results from patients with well controlled blood pressure were compared with those with uncontrolled hypertension. It was hypothesized that patients with well controlled blood pressure would have higher self-efficacy scores than those with uncontrolled blood pressure.

Confirmatory Factor Analysis was performed using the statistical software LISREL 8.80. The Model Fitness was evaluated using Chi-square $\left(\chi^{2}\right)$, root mean square error of approximation (RMSEA), Comparative Fit Index (CFI), and Tucker-Lewis Index (TLI). Model modifications were completed based on modification index and the results of reliability analysis. The criteria used to determine a good
Model Fitness were a non-significant Chi-square results, the ratio between Chi-square and its degrees of freedom $<2.0$, the value of TLI and CFI $\geq 0.95$, and the value of RMSEA $<0.06$ [21, 22].

\subsection{The Use of Persian Version of MASES in Hypertensive Patients}

This study was conducted in the health centers affiliated to Qazvin University of Medical Sciences. This study was approved by the Human Research Ethics Committee of Qazvin University of Medical Sciences. All participants have signed a consent form.

Based on the convenience sampling, 184 patients with hypertension who were referred to the health service centers in Qazvin were recruited to participate in this study. Inclusive criteria were: 18 years and above, proficient in Persian language (understanding Persian language), literacy, using anti-hypertensive drugs for at least a year, volunteered to participate in the study, and have regular follow-up treatments for hypertension. The patients were excluded if they had physical or cognitive disorders or were unwilling to participate. The response rate was $95.83 \%$. Eight patients who were eligible for the study were excluded due to unwillingness to participate. Statistical tests showed that there was no significant difference between excluded and included patients in terms of sociodemographic variables.

The MASES developed by Ogedegbe and colleagues [9] has been used to assess the self-efficacy in the adherence to anti-hypertensive medications in patients with high mortality risk. The MASES is a patient-centered and self-administered questionnaire that consists of 26 items. The patient were asked to rate their confidence of taking antihypertensive medications in different conditions using a three-point scale $(1=$ unsure, $2=$ somewhat sure, and $3=$ very sure). This was performed by trained researchers when the patients were attended in the waiting room before their medical consultations. The total score of the 26 items was then summed up. The score is positively correlated with the level of self-efficacy, with higher score reflecting higher self-efficacy. Original factor structure showed the uni-dimensionality of the scale because the majority of items in this structure were loaded on Factor 1. In addition to the original MASES questions, several questions were designed to measure the general characteristics (socio-demographic) of the patient, including age, education, marital status, job status, socioeconomic status, and the number of medications used for controlling hypertension.

Blood pressure was measured twice with an interval of 10 min for each patient using an automated blood cuff by a general practitioner who was blind to the participants during the measurement. The average of the two 
measurements was used [23]. Patients were resting in a quiet room for $10 \mathrm{~min}$ before the first measurement and the measurement was taken under the same condition [24]. Blood pressure was measured by a general practitioner who was blind to the participants. $\mathrm{P}<0.05$ was considered as significant for all the tests (SPSS 17, Chicago, IL, USA).

\section{Results}

It only took $5 \mathrm{~min}$ to complete the questionnaire and the questions are easy to be understood by the patients. Cronbach's alpha coefficient of the Persian version of the MASES was $>0.92$, suggesting that this version can yield consistent results over the time (25).

The general characteristics of the participants are shown in Table 1 . The age range of the participants was between 18 and 73 years old. Most participants in the study were

Table 1 General characteristics of the sample $(n=184)$

\begin{tabular}{|c|c|c|}
\hline Characteristics & Total & Percentage \\
\hline Age $($ mean \pm SD) & $61.55 \pm 12.83$ & \\
\hline \multicolumn{3}{|l|}{ Gender } \\
\hline Male & 101 & 54.89 \\
\hline Female & 83 & 45.11 \\
\hline \multicolumn{3}{|l|}{ Marital status } \\
\hline Married & 119 & 64.66 \\
\hline Separated/divorced & 17 & 9.24 \\
\hline Widow & 44 & 23.92 \\
\hline Never married & 4 & 2.18 \\
\hline \multicolumn{3}{|l|}{ Education level } \\
\hline Primary school & 84 & 45.66 \\
\hline High school & 85 & 46.18 \\
\hline University degree & 15 & 8.16 \\
\hline \multicolumn{3}{|l|}{ Type of insurance } \\
\hline Social welfare & 98 & 53.26 \\
\hline Remedial service & 58 & 31.53 \\
\hline Self-paid & 22 & 11.95 \\
\hline No insurance & 6 & 3.26 \\
\hline \multicolumn{3}{|l|}{ Employment } \\
\hline Unemployed & 126 & 68.47 \\
\hline Employed & 58 & 31.53 \\
\hline \multicolumn{3}{|l|}{ Economic status } \\
\hline Low & 37 & 20.11 \\
\hline Middle & 83 & 45.11 \\
\hline Good & 55 & 29.88 \\
\hline Excellent & 9 & 4.90 \\
\hline Duration of hypertension (years) & $6.00 \pm 4.05$ & \\
\hline Number of medication & $1.34 \pm 0.85$ & \\
\hline Duration of treatment (years) & $5.3 \pm 3.64$ & \\
\hline
\end{tabular}

married and their education levels were below tertiary degree. The majority of the patients were covered by the health insurance. Two thirds of the patients were unemployed, while most of the patients had fair or good economic status. The duration of the disease varies between patients, as well as the number of the medication (Table 1).

Table 2 shows the self-efficacy scores, item-to-total correlation, kappa coefficients, and Cronbach's alpha value among 184 patents. Mean self-efficacy scores were ranged from 1.72 to 2.28 with the standard deviations ranged from 0.51 to 0.81 . For all items, kappa values were ranged from 0.28 to 1 . The kappa value was less than 0.4 for two items, while it was between $0.4-0.6$ for 13 items. There are eleven items with kappa values greater than 0.6. The Cronbach's alpha value was 0.91 for all 26 items. The item-to-total correlation coefficients are between 0.248 and 0.685 for all items, which were all acceptable except for the Question 12 which reads, "When you are afraid that the medications may affect your sexual performance". Although the itemtotal correlation value for this question was less than 0.3 , it was not excluded from the current study. This is because that its Chronbach's alpha value was 0.917 and the removal of this question did not change the internal consistency. In Addition, given that sexual disability is a barrier that is mentioned frequently by the patients, it was retained for its clinical importance, which has also been included in the original MASES by Ogedegbe and coworkers.

Table 3 shows the factor loadings of each question, Eigen values, and the proportion of total variance against each factor. The KMO Measure value of the data was 0.857 , which suggests that there was sufficient and high variability in the data to perform component analysis. The results of Bartlett Test of Sphericity (approximate $\chi^{2}$ $(325)=1780.5, \mathrm{P}<0.001)$ as well as KMO confirmed the factorability of the data. An Exploratory Principal Components Factor Analysis performed on the 26 items in the MASES revealed a five-factor solution using the minimum Eigen value criteria $(<1)$. These five factors contributed to about $67.8 \%$ of the total variance (Table 3). Twenty out of 26 items were loaded in Factor 1. Two items were loaded in Factors 2 and 3 and one item was loaded in Factors 4 and 5. Six items $(6,15,17,19,23$ and 24) had substantial loadings on more than one factor (items with loadings $\geq 0.4$ ). Factor loading of all the items were acceptable.

The comparisons of Self-efficacy scores between the patients with uncontrolled hypertension and those with well-controlled blood pressure are shown in Table 4. The former had significantly higher systolic $(\mathrm{P}<0.05)$ and diastolic blood pressure $(\mathrm{P}<0.05)$ than the latter (Table 4). The average efficacy score was higher in the patients with controlled blood pressure than those with uncontrolled hypertension $(\mathrm{P}<0.05)$, in 16 out of 26 questions (Table 4).

$\Delta$ Adis

$\begin{array}{lll}\text { Journal : Large 40292 } & \text { Dispatch : 13-5-2015 } & \text { Pages : } \mathbf{9} \\ \text { Article No. : } \mathbf{1 0 1} & \square \text { LE } & \square \text { TYPESET } \\ \text { MS Code : } \quad \text { BPCP-D-15-00018 } & \checkmark_{\text {CP }} & \checkmark \text { DISK }\end{array}$


Table 2 Item analysis of the medication adherence self-efficacy scale

\begin{tabular}{|c|c|c|c|c|}
\hline & $\begin{array}{l}\text { Self-efficacy } \\
\text { (mean } \pm \text { SD) }\end{array}$ & $\begin{array}{l}\text { Kappa } \\
\text { coefficients }\end{array}$ & $\begin{array}{l}\text { Cronbach's } \\
\text { alpha }\end{array}$ & ITC \\
\hline \multicolumn{5}{|l|}{ How confident are you in taking your blood pressure medications? } \\
\hline 1. When you are busy at home & $1.92 \pm 0.73$ & 0.55 & 0.918 & 0.415 \\
\hline $\begin{array}{l}\text { 2. When you are at work/When you are busy with your daily } \\
\text { routines }\end{array}$ & $1.87 \pm 0.76$ & 0.63 & 0.915 & 0.507 \\
\hline 3. When there is no one to remind you & $2.08 \pm 0.71$ & 0.48 & 0.915 & 0.506 \\
\hline 4. When you worry about taking them for the rest of your life & $1.92 \pm 0.78$ & 0.54 & 0.913 & 0.580 \\
\hline 5. When they cause some side effects & $1.78 \pm 0.51$ & 0.47 & 0.918 & 0.430 \\
\hline 6. When they cost a lot of money & $2.05 \pm 0.75$ & 0.46 & 0.914 & 0.535 \\
\hline $\begin{array}{l}\text { 7. When you come home late from work/when your work finishes } \\
\text { late }\end{array}$ & $1.96 \pm 0.66$ & 0.72 & 0.914 & 0.569 \\
\hline 8. When you do not have symptoms & $1.82 \pm 0.80$ & 0.46 & 0.917 & 0.537 \\
\hline 9. When you are with family members & $2.01 \pm 0.76$ & 0.61 & 0.913 & 0.454 \\
\hline 10. When you are in a public area & $1.89 \pm 0.8$ & 0.42 & 0.916 & 0.551 \\
\hline 11. When you are afraid of becoming dependent on them & $1.82 \pm 0.77$ & 0.47 & 0.917 & 0.484 \\
\hline $\begin{array}{l}\text { 12. When you are afraid that they may affect your sexual } \\
\text { performance }\end{array}$ & $1.81 \pm 0.77$ & 0.63 & 0.917 & 0.248 \\
\hline 13. When the time to take them is between your meals & $2.08 \pm 0.68$ & 0.65 & 0.912 & 0.475 \\
\hline 14. When you feel that you don't need them & $1.73 \pm 0.73$ & 0.61 & 0.916 & 0.622 \\
\hline 15. When you are traveling & $1.78 \pm 0.71$ & 0.78 & 0.903 & 0.475 \\
\hline 16. When you take them more than once a day & $1.95 \pm 0.72$ & 1.00 & 0.916 & 0.370 \\
\hline 17. If they sometimes make you feel tired & $1.81 \pm 0.68$ & 0.28 & 0.915 & 0.485 \\
\hline 18. If they sometimes makes you feel dizzy & $1.81 \pm 0.77$ & 0.57 & 0.913 & 0.512 \\
\hline 19. When you have other medications to take & $2.04 \pm 0.75$ & 0.61 & 0.909 & 0.570 \\
\hline 20. When you feel well & $1.94 \pm 0.83$ & 0.55 & 0.917 & 0.665 \\
\hline 21. If they make you want to urinate while away from the toilet & $1.72 \pm 0.75$ & 0.65 & 0.915 & 0.449 \\
\hline \multicolumn{5}{|l|}{ How confident are you that you can carry out the following tasks? } \\
\hline $\begin{array}{l}\text { 22. Get refills for your blood pressure medications before they run } \\
\text { out }\end{array}$ & $2.28 \pm 0.75$ & 0.84 & 0.915 & 0.517 \\
\hline 23. Fill your prescriptions regardless of the cost & $2.18 \pm 0.79$ & 0.45 & 0.915 & 0.510 \\
\hline 24. Make your medications as part of your daily routine & $2.12 \pm 0.80$ & 0.60 & 0.909 & 0.685 \\
\hline 25. Always remember to take your blood pressure medications & $2.05 \pm 0.81$ & 0.29 & 0.911 & 0.630 \\
\hline 26. Take your blood pressure medications for the rest of your life & $1.96 \pm 0.83$ & 0.47 & 0.916 & 0.472 \\
\hline
\end{tabular}

ITC item-total scale correlation; $S D$ standard deviation

Hypertensive patients also showed lower medication adherence self-efficacy compared with normotensive individuals and pre-hypertensive patients (Hypertensive-Normal systolic, $\mathrm{Z}_{\mathrm{MWU}}=-2.236, \mathrm{P}=0.025$, HypertensiveNormal systolic, $\mathrm{Z}_{\mathrm{MWU}}=-3.025, \mathrm{P}=0.002$, Hypertensive-Normal diastolic, $\mathrm{Z}_{\mathrm{MWU}}=-2.716, \quad \mathrm{P}=0.007$, Hypertensive-Normal diastolic, $\mathrm{Z}_{\mathrm{MWU}}=-3.147, \quad \mathrm{P}=$ 0.002, (Table 5).

\section{Discussion}

This study modified the English version of MASES into Persian language, according to the specificity of Iranian culture. The validity and reliability were confirmed in individuals with normal blood pressure and hypertensive patients with/without well controlled blood pressure, where patients with uncontrolled hypertension had significantly lower self-efficacy to adhere to anti-hypertensive medication. The later clearly played a causal role in their uncontrolled hypertension.

The burden of chronic diseases, such as hypertension, is incasing in developing countries [25]. Poor self-efficacy as a contributing factor to increased rate of uncontrolled hypertension shall receive more attention in these countries. Despite the fact that this study was conducted in a developing country using a modified MASES on the adherence to hypertension treatment, the results are consistent with the studies using the original MASES in developed countries, where it has been suggested that non-adherence to

\begin{tabular}{|l|lll|}
\hline Journal : Large 40292 & Dispatch : 13-5-2015 & Pages : 9 \\
Article No. : $\mathbf{1 0 1}$ & $\square$ LE & $\square$ TYPESET \\
MS Code : BPCP-D-15-00018 & $\sim_{\mathrm{CP}}$ & $\checkmark$ DISK \\
\hline
\end{tabular}


Table 3 Principal component analysis of the MASES

\begin{tabular}{|c|c|c|c|c|c|}
\hline \multirow[t]{2}{*}{ Item } & \multicolumn{5}{|c|}{ Factors and loading } \\
\hline & 1 & 2 & 3 & 4 & 5 \\
\hline 1. When you are busy at home & 0.673 & & & & \\
\hline 2. When you are at work/When you are busy with daily routines & 0.677 & & & & \\
\hline 4. When you worry about taking them for the rest of your life & 0.721 & & & & \\
\hline 5. When they cause some side effects & 0.703 & & & & \\
\hline 6. When they cost a lot of money & 0.702 & & & 0.493 & \\
\hline 7. When you come home late from work/when your daily works finish late & 0.741 & & & & \\
\hline 8. When you do not have symptoms & 0.740 & & & & \\
\hline 11. When you are afraid of being dependent on them & 0.735 & & & & \\
\hline 12. When you are afraid that they may affect your sexual performance & 0.775 & & & & \\
\hline 13. When the time to take them is between your meals & 0.761 & & & & \\
\hline 14. When you feel you do not need them & 0.691 & & & & \\
\hline 15. When you are traveling & 0.669 & & & & 0.533 \\
\hline 16. When you take them more than once a day & 0.577 & & & & \\
\hline 19. When you have other medications to take & 0.568 & & & & 0.466 \\
\hline 20. When you feel well & 0.577 & & & & \\
\hline 21. If they make you want to urinate while away from the toilet & 0.677 & & & & \\
\hline 23. Fill your prescriptions regardless of the cost & 0.718 & & 0.561 & & \\
\hline 24. Make your blood pressure medications as part of your daily routine & 0.729 & & 0.603 & & \\
\hline 25. Always remember to take your blood pressure medications & 0.742 & & & & \\
\hline 26. Take your blood pressure medications for the rest of your life & 0.773 & & & & \\
\hline 9. When you are with family members & & 0.725 & & & \\
\hline 10. When you are in a public area & 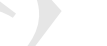 & 0.633 & & & \\
\hline 17. If they sometimes make you feel tired & 0.619 & & 0.750 & & \\
\hline 18. If they sometimes make you feel dizzy & & & 0.730 & & \\
\hline 22. Get refills for your blood pressure medications before they run out & & & & 0.759 & \\
\hline 3. When there is no one to remind you & & & & & 0.655 \\
\hline Eigen value & 11.12 & 1.84 & 1.70 & 1.56 & 1.32 \\
\hline$\%$ explained variance & 42.76 & 7.09 & 6.55 & 6.00 & 5.41 \\
\hline Cumulative $\%$ explained variance & 42.76 & 49.85 & 56.40 & 62.40 & 67.81 \\
\hline
\end{tabular}

anti-hypertensive medication is a key issue in hypertension management $[4,26]$. Therefore, it is necessary to recognize the poor self-efficacy to antihypertensive medication and its cause factors, in order to impose behaviour changes in such patients to improve their blood pressure control.

The concept of adherence used in this study is "a person's behaviours to take anti-hypertensive medications and modify their diet and/or lifestyle correspond to the recommendations by the clinician, according to the guideline of the World Health Organization [8]. Adherence to a medication regimen requires a set of behaviors that include obtaining the medication, timely administration of the correct dose via recommended route, and keeping up with the course of the treatment. The importance of adherence to medication is well accepted. However, success in keeping these behaviors can be hampered by many factors related to aging. The loss of sensory function, disturbances of memory and cognition, depression, and lifestyle changes due to retirement can all disrupt the routine to maintain regular medication [27-29]. The cessation of medication can lead to symptom deterioration, increased chance of hospitalizations, and increased morbidity and mortality [30, 31].

As the adherence to anti-hypertensive therapy shall be considered as a precaution of cardiovascular morbidity and mortality, self-efficacy becomes an important factor to assess medication adherence behaviour. However, the association between self-efficacy and adherence to anti-hypertensive therapy has not been well-characterised in Iran. The current study using a Persian version of the MASE among Iranian patients with hypertension showed that selfefficacy is a strong determinant of medication adherence in hypertensive patients, which is also closely related to their blood pressure control.

\begin{tabular}{|c|c|c|c|c|}
\hline & Journal : Large 40292 & Dispatch & 13-5-2015 & Pages: 9 \\
\hline & $\begin{array}{l}\text { Article No. : } 101 \\
\text { MS Code : } \\
\text { BPCP-D-15-00018 }\end{array}$ & $\begin{array}{l}\square \text { LE } \\
\mathscr{V}_{\mathrm{CP}} \\
\end{array}$ & & $\begin{array}{l}\square \text { TYPESET } \\
\boldsymbol{V} \text { DISK } \\
\end{array}$ \\
\hline
\end{tabular}


Table 4 The MASES scores between patients with uncontrolled hypertension and those with well-controlled blood pressure

Table 5 Patients' self-efficacy related to blood pressure
Items

Hypertensive patients

1. When you busy at home

Uncontrolled Controlled

2. When you are at work/When you are busy with daily routines

$2.54 \pm 0.64 \quad 2.75 \pm 0.61$

3. When there is no one to remind you

$2.11 \pm 0.55 \quad 2.31 \pm 0.82$

4. When you worry about taking them for the rest of your life

$2.83 \pm 0.81 \quad 3.00 \pm 0.00$

5 . When they cause some side effects

$2.66 \pm 0.46 \quad 2.87 \pm 0.58$

6. When they cost a lot of money

7. When you come home late from work/when your work finishes late

8 . When you do not have symptoms

9. When you are with family members

10. When you are in a public area

11. When you are afraid of becoming dependent on them

12. When you are afraid they may affect your sexual performance

13. When the time to take them is between your meals

14. When you feel you do not need them

15 . When you are traveling

16. When you take them more than once a day

17. If they sometimes make you tired

18. If they sometimes makes you feel dizzy

19. When you have other medications to take

20. When you feel well

21. If they make you want to urinate while away from the toilet

$2.43 \pm 0.49 \quad 2.79 \pm 0.71$

$2.37 \pm 0.87 \quad 2.54 \pm 0.81$

$2.23 \pm 0.87 \quad 2.21 \pm 0.55$

$2.36 \pm 0.78 \quad 2.77 \pm 0.63$

$2.75 \pm 0.60 \quad 2.75 \pm 0.90$

$2.42 \pm 0.57 \quad 2.80 \pm 0.54$

$2.77 \pm 0.90 \quad 3.00 \pm 0.00$

$2.39 \pm 0.82 \quad 2.21 \pm 0.93$

$2.55 \pm 0.64 \quad 2.76 \pm 0.62$

$2.63 \pm 0.63 \quad 2.82 \pm 0.92$

$2.41 \pm 0.84 \quad 2.62 \pm 0.76$

$2.52 \pm 0.67 \quad 2.54 \pm 0.70$

$2.21 \pm 0.99 \quad 2.38 \pm 0.00$

$1.98 \pm 0.53 \quad 1.83 \pm 0.78$

$2.51 \pm 0.80 \quad 2.50 \pm 0.63$

$2.43 \pm 0.76 \quad 2.64 \pm 0.73$

$2.33 \pm 0.60 \quad 2.12 \pm 0.95$

22. Get refills for your blood pressure medications before they run out

$2.60 \pm 0.49 \quad 2.44 \pm 0.84$

23. Fill your prescriptions regardless of the cost

24. Make your blood pressure medications as part of your daily routine

25. Always remember to take your blood pressure medications

$2.46 \pm 0.54 \quad 2.63 \pm 0.66$

$2.81 \pm 0.73 \quad 2.76 \pm 0.62$

$2.50 \pm 0.78 \quad 2.42 \pm 0.95$

26. Take your blood pressure medications for the rest of your life
The self-efficacy, as stated by Bandura, is a self-belief of the ability to perform some difficult tasks, relevant to this study: taking complicated treatment regimens [32]. This can be evaluated by the questions on patient's attitude such as "I can do it", or in hypertensive patients "I can take my anti-hypertensive medication consistently". The latter statement has been evaluated in this study using the Persian
MASES. Several studies have suggested the beneficial effects on health outcomes by the implementing self-efficacy to continuing treatment programs [33, 34]. However, most of these studies were on life-threatening infectious diseases, such as HIV infection and chronic viral hepatitis [35-39]. In addition, in previous studies, self-efficacy has been correlated with practicing self-care practices for the

\begin{tabular}{lll} 
Journal : Large 40292 & Dispatch : 13-5-2015 & Pages : 9 \\
Article No. : $\mathbf{1 0 1}$ & $\square$ LE & $\square$ TYPESET \\
MS Code : BPCP-D-15-00018 & $\boldsymbol{\sim}_{\text {CP }}$ & $\checkmark$ DISK \\
\hline
\end{tabular}


other chronic conditions [40, 41]. This study demonstrated the significant role of self-efficacy in treatment adherence among hypertensive patients, with similar finding as the previous studies $[18,42]$.

The findings of our study obtained from the Principal Component Analysis suggested a structure of one-single factor of the questionnaire. Although a 5-factor structure was yielded, the Factor 1 is the dominant one, and the other four factors could also be easily loaded onto factor 1 . Thus the unidimensionality of the Persian MASE is consistent with the previous studies using the English MASES [9, 17, 18]. Ideally, at least 100-200 patients are required for the Factor Analysis [43]. In our study, 189 patients participated, which makes the analysis result acceptable to validate the MASES. This was further confirmed by the comparison between the patients with controlled and uncontrolled blood pressure. In this study, high value of Cronbach's alpha test was recognized and thus the item redundancy was assessed. Although, several items were closely correlated to each other, there was no redundancy in the other items. This is because that each item refers to different situation, all of which are essential to evaluate the attitude towards self-efficacy and practice. The high internal consistency in this study suggests the reliability of the questionnaire. Many currently available scales from the other language focus on patient's self-esteem or self-report on the empowerment to take prescribed medication regardless of patient's concerns [37, 44]. Therefore, the Persian MASES may offer a more holistic approach to determine the self-efficacy in medication adherence than the other measures due to the recognition of the patient's perception towards medications.

Moreover, based on the present and previous studies, this MASES can distinguish the self-efficacy between hypertensive patients with controlled and uncontrolled blood pressure. Therefore, it can be used as a tool for the clinicians to monitor their patients' confidence of using antihypertensive medications. If the patients know little about their health situation and the benefit of the medications, they are less likely to comply to their medications [45]. Therefore, MASES can be a good tool to assess the effectiveness of the interventions to reinforce medical knowledge in the patients, in order to increase the selfefficacy of the patients to medication adherence [17]. In our study, the patients with uncontrolled hypertension had significantly lower self-efficacy than those with well controlled blood pressure, which is similar to a previous study in patients with hypertensive histories for more than one year, but not newly diagnosed patients [46]. It has been suggested that the longer duration of the disease could contribute to a higher level of self-efficacy.

There are still some limitations in this study. Firstly, Convenience Sampling was used which may affect the generality of the results. Further research is needed to use random sampling in a larger scale including participants from multiple health centers in Iran. Secondly, our study relied on self-reporting, where certain biases of the patients may affect the final results [47]. Therefore, alternative options, such as electronic monitors or more objective reports from the carers, are needed to achieve more accurate information on medication adherence. Finally, the MASES only questioned the current beliefs on medication adherence, where it does not reflect the medical adherence in the past, which may also affect the overall blood pressure control.

\section{Conclusion}

The Persian MASES is useful to improve the evaluation of confidence in medication adherence among patients with hypertension. Thus, it can be used as a practical tool to assess the self-efficacy among Iranian patients with hypertension in medical practice, clinical studies, or clinical trials.

Acknowledgments The authors would like to thank the participants of the study for sharing their experiences with us. The authors would also like to thank Miss Mahdieh Pakpour for his ${ }_{\Omega}$ constructive help for data collection.

\section{References}

1. Kearney PM, et al. Global burden of hypertension: analysis of worldwide data. Lancet. 2005;365(9455):217-23.

2. Mancia G, et al. 2013 ESH/ESC Guidelines for the management of arterial hypertension: the Task Force for the management of arterial hypertension of the European Society of Hypertension (ESH) and of the European Society of Cardiology (ESC). J Hypertens. 2013;31(7):1281-357.

3. Grossman Y, Shlomai G, Grossman E. Treating hypertension in type 2 diabetes. Expert Opin Pharmacother. 2014;15(15):2131-40.

4. Krousel-Wood M, et al. Medication adherence: a key factor in achieving blood pressure control and good clinical outcomes in hypertensive patients. Curr Opin Cardiol. 2004;19(4):357-62.

5. Chobanian AV, et al. Seventh report of the Joint National Committee on Prevention, Detection, Evaluation, and Treatment of High Blood Pressure. Hypertension. 2003;42(6):1206-52.

6. Chobanian AV, et al. The seventh report of the Joint National Committee on Prevention, Detection, Evaluation, and Treatment of High Blood Pressure: the JNC 7 report. JAMA. 2003;289(19): 2560-72.

7. Giverhaug T, Falck A, Eriksen BO. Effectiveness of antihypertensive treatment in chronic renal failure: to what extent and with which drugs do patients treated by nephrologists achieve the recommended blood pressure? J Hum Hypertens. 2004;18(9): 649-54.

8. Sabaté E. Adherence to long term therapy: evidences for action. Switzerland: World Health Organization; 2003.

9. Ogedegbe G, et al. Development and evaluation of a medication adherence self-efficacy scale in hypertensive African-American patients. J Clin Epidemiol. 2003;56(6):520-9.

\begin{tabular}{|l|lll|}
\hline Journal : Large 40292 & Dispatch : 13-5-2015 & Pages : 9 \\
Article No. : 101 & $\square$ & $\square$ TY & $\checkmark$ TYSESET \\
\hline MS Code : BPCP-D-15-00018 & $\sim_{\text {CP }}$ & $\checkmark$ DISK \\
\hline
\end{tabular}


10. Leventhal H, Meyer D, Gutmann M. The role of theory in the study of compliance to high blood pressure regimes. In: Leventhal H, Meyer D, Gutmann M, editors. Patient compliance to prescribed antihypertensive medication regimens: a report to the National Heart, Lung, and Blood Institute. Washington, DC: U.S. Department of Heart and Human Services; 1980.

11. Dunbar-Jacob J, Dwyer EJ. Compliance with antihypertensive regimens: a review of the research in the 1980s. Ann Behav Med. 1991;13:32-9.

12. Bandura A. Social foundations of thought and action. Englewood Cliffs: Prentice Hall; 1986.

13. Bosworth H, Oddone E, Weinberger M. Patient treatment adherence: Concepts, interventions and measurement. New York: Lawrence Earlbaum Associates; 2005.

14. Bandura A. Self-efficacy mechanism in human agency. Am Psychol. 1982;97:122.

15. McCann T, Clar E, Lu S. The self-efficacy model of medication adherence in chronic mental illness. J Clin Nurs. 2008;17: 329-40.

16. Bandura A. Self-efficacy: the exercise of control. New York: Wiley; 1994.

17. Gozum S, Hacihasanoglu R. Reliability and validity of the Turkish adaptation of medication adherence self-efficacy scale in hypertensive patients. Eur J Cardiovasc Nurs. 2009;8(2):129-36.

18. Fernandez $\mathrm{S}$, et al. Revision and validation of the medication adherence self-efficacy scale (MASES) in hypertensive African Americans. J Behav Med. 2008;31(6):453-62.

19. Beaton DE, et al. Guidelines for the process of cross-cultural adaptation of self-report measures. Spine (Phila Pa 1976). 2000;25(24):3186-91.

20. Nunnally JC, Bernstein IR. Psychometric theory. 3rd ed. New York: McGraw-Hill; 1994.

21. Bollen KA, Long JS, Models Testing structural equation. Thousand Oaks. CA: Sage Publications; 1993.

22. Hu L, Bentler PM. Cutoff criteria for fit indexes in covariance structure analysis: conventional criteria versus new alternatives. Struct Equ Model. 1999;6:1-55.

23. Pickering TG, et al. Recommendations for blood pressure measurement in humans and experimental animals: part 1: blood pressure measurement in humans: a statement for professionals from the Subcommittee of Professional and Public Education of the American Heart Association Council on High Blood Pressure Research. Circulation. 2005;111(5):697-716.

24. Eguchi K, et al. Consistency of blood pressure differences between the left and right arms. Arch Intern Med. 2007;167(4):388-93.

25. Koopman JJ, et al. Hypertension in developing countries. Lancet. 2012;380(9852):1471-2

26. Bosworth HB, et al. Take Control of Your Blood Pressure (TCYB) study: a multifactorial tailored behavioral and educational intervention for achieving blood pressure control. Patient Educ Couns. 2008;70(3):338-47.

27. Brown $\mathrm{C}$, et al. Beliefs about antidepressant medications in primary care patients: relationship to self-reported adherence. Med Care. 2005;43(12):1203-7.

28. Gehi AK, et al. Self-reported medication adherence and cardiovascular events in patients with stable coronary heart disease: the heart and soul study. Arch Intern Med. 2007;167(16):1798-803.
29. Schlenk EA, Dunbar-Jacob J, Engberg S. Medication non-adherence among older adults: a review of strategies and interventions for improvement. J Gerontol Nurs. 2004;30(7):33-43.

30. McHorney CA. The adherence estimator: a brief, proximal screener for patient propensity to adhere to prescription medications for chronic disease. Curr Med Res Opin. 2009;25(1):215-38.

31. Oyekan E, et al. The B-SMART appropriate medication-use process: a guide for clinicians to help patients-part 1: barriers, solutions, and motivation. Perm J. 2009;13(1):62-9.

32. Bandura A, Locke EA. Negative self-efficacy and goal effects revisited. J Appl Psychol. 2003;88(1):87-99.

33. Ciere Y, Cartwright M, Newman SP. A systematic review of the mediating role of knowledge, self-efficacy and self-care behaviour in telehealth patients with heart failure. J Telemed Telecare. 2012;18(7):384-91.

34. Fors A, et al. The Cardiac Self-Efficacy Scale, a useful tool with potential to evaluate person-centred care. Eur J Cardiovasc Nurs, 2014.

35. Louw J, Peltzer K, Chirinda W. Correlates of HIV risk reduction self-efficacy among youth in South Africa. Sci World J. 2012;2012:817315.

36. Waldrop-Valverde D, Dong C, Ownby RL. Medication-taking self-efficacy and medication adherence among HIV-infected cocaine users. J Assoc Nurses AIDS Care, 2012.

37. Huang L, et al. Self-efficacy, medication adherence, and quality of life among people living with HIV in Hunan Province of China: a questionnaire survey. J Assoc Nurses AIDS Care, 2012.

38. Bonner JE, Esserman D, Evon DM. Reliability and validity of a self-efficacy instrument for hepatitis $\mathrm{C}$ antiviral treatment regimens. J Viral Hepat. 2012;19(5):316-26.

39. Grow JM, Christopher SA. Breaking the silence surrounding hepatitis $\mathrm{C}$ by promoting self-efficacy: hepatitis $\mathrm{C}$ public service announcements. Qual Health Res. 2008;18(10):1401-12.

40. Sharoni SK, Wu SF. Self-efficacy and self-care behavior of Malaysian patients with type 2 diabetes: a cross sectional survey. Nurs Health Sci. 2012;14(1):38-45.

41. Warren-Findlow J, Seymour RB, Brunner LR. Huber, The association between self-efficacy and hypertension self-care activities among African American adults. J Community Health. 2012;37(1):15-24.

42. Hacihasanoglu R, Gozum S, Capik C. Validity of the Turkish version of the medication adherence self-efficacy scale-short form in hypertensive patients. Anadolu Kardiyol Derg. 2012;12(3):241-8

43. Sapnas KG, Zeller RA. Minimizing sample size when using exploratory factor analysis for measurement. J Nurs Meas. 2002;10(2):135-54.

44. Gonzalez JS, et al. The validity of medication adherence selfreports in adults with Type 2 diabetes. Diabetes Care, 2012.

45. Park M. Effects of interactive pictorial education on community dwelling older adult's self efficacy and knowledge for safe medication. J Korean Acad Nurs. 2011;41(6):795-804.

46. Morris $\mathrm{AB}$, et al. Factors associated with drug adherence and blood pressure control in patients with hypertension. Pharmacotherapy. 2006;26(4):483-92.

47. Ho LY, Lau AS. Do self-report measures of social anxiety reflect cultural bias or real difficulties for Asian American college students? Cultur Divers Ethnic Minor Psychol. 2011;17(1):52-8.

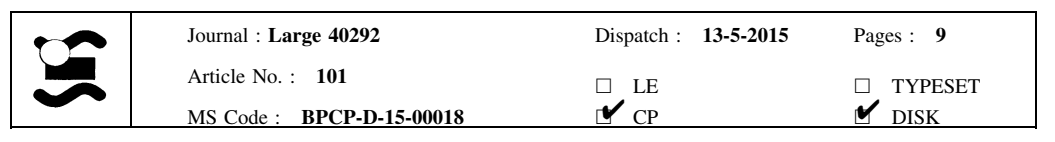


Journal : 40292

Article : 101

\section{黛 Springer}

the language of science

\section{Author Query Form}

\section{Please ensure you fill out your response to the queries raised below and return this form along with your corrections}

\section{Dear Author}

During the process of typesetting your article, the following queries have arisen. Please check your typeset proof carefully against the queries listed below and mark the necessary changes either directly on the proof/online grid or in the 'Author's response' area provided below

\begin{tabular}{|l|l|l|}
\hline Query & Details Required & Author's Response \\
\hline AQ2 & Kindly update the reference $[34,36,37,44]$ with volume and page range if possible. & \\
\hline AQ1 & $\begin{array}{l}\text { Both P value and H value are present in last column of Table } 5 \text { but the column head is given as P value. } \\
\text { Kindly check and amend if necessary. }\end{array}$ & \\
\hline
\end{tabular}

